\title{
Accuracy of fine needle aspiration compared to core needle biopsy in breast masses
}

\author{
Mohammad Moazeni Bistgani $^{1 \mathbb{D}}$, Monem Basravi ${ }^{2 *}{ }^{\mathbb{Q}}$, Abdolmajid Taheri $^{3}$, Shahla Taheri ${ }^{3}$, Soleyman Kheiri ${ }^{4}$ \\ ${ }^{1}$ Associate Professor, Department of Surgery, Shahrekord University of Medical Sciences, Shahrekord, Iran \\ ${ }^{2}$ General Surgery, Department of Surgery, Isfahan University of Medical Sciences, Isfahan, Iran \\ ${ }^{3}$ Assistant Professor, Department of Pathology, Shahrekord University of Medical Sciences, Shahrekord, Iran \\ ${ }^{4}$ Associate Professor, Department of Statistics, Shahrekord University of Medical Sciences, Shahrekord, Iran
}

*Corresponding Author: Monem Basravi, Department of Surgery, Isfahan University of Medical Sciences, Isfahan, Iran. Email: monem_basravi@yahoo.com

\begin{abstract}
Background and aims: Breast cancer is one of the main causes of death in women, the early diagnosis of which is made by physical examination, mammography, ultrasound, and biopsy of breast masses. The aim of this study was to assess the diagnostic accuracy of fine needle aspiration (FNA) compared to core needle biopsy (CNB) in breast masses.

Methods: The current descriptive study was conducted in Kashani and Hajar hospitals in 2015. And a total of 200 patients diagnosed with breast masses participated in this study. First, patients referred to the clinic, received local anesthesia in the area, and then underwent FNA using 10 cc syringes and 23G needles, and simultaneously CNB specimens were taken by a special needle for diagnosis. FNA and CNB specimens were transferred to the Pathology Department with a few day interval for cytological interpretation.

Results: The sensitivity and specificity of FNA compared to CNB in the diagnosis of malignant breast masses were $83.9 \%$ and $89.9 \%$, respectively. Moreover, the positive and negative predictive values of FNA for breast masses were $78.8 \%$ and $92.5 \%$, respectively. The accuracy of FNA test for breast masses was also $0.88 \%$.

Conclusion: According to the results of this study, FNA test had a high sensitivity, specificity, and predictive value in the diagnosis of breast masses. Therefore, it could be used as an appropriate diagnostic tool, and could obviously save many costs as well.

Keywords: Fine needle aspiration; Core needle biopsy; Breast mass
\end{abstract}

Received: 26 June 2016, Accepted: 21 August 2018, ePublished: 4 April 2019

\section{Introduction}

Breast cancer is one of the most common malignancies in today's societies (1) and one of the leading causes of death among women, the early diagnosis of which is an important factor in reducing female mortality $(2,3)$. In addition, breast cancer is the leading cancer in women and accounts for $25.4 \%$ of all malignancies (4). Diagnosis of breast cancer is made by means of clinical examination, mammography, ultrasound, and biopsy of the breast mass.

Mammography is one of the most common noninvasive methods, which is used for breast examination, and has diagnostic value in both screening and detecting the disease cases. Another non-invasive technique used for breast examination, especially for dense breasts, is ultrasound (5). The value of ultrasound in studies has been reported to be $70 \%-90 \%$ (6-8). Further, breast biopsy is the most common and definitive diagnostic method of breast cancer. About 1800000 breast biopsies are reportedly taken each year in the United States, approximately 70\%$80 \%$ of which are related to benign breast masses $(9,10)$. Fine needle aspiration (FNA), core needle biopsy (CNB), and excisional biopsy are among the methods that are used for diagnosis of breast masses $(11,12)$. Most of the malignant masses are diagnosed by the cytology of FNA or CNB before surgery, and definitive surgical treatment can be scheduled accordingly (13). FNA is one of the common tests used for the diagnosis of breast masses, whose success rate and diagnostic accuracy depends on physical examination and radiological studies, especially in small and impalpable masses $(14,15)$. It is a fast test, but not in the first line of screening. If this test is conducted under ultrasound or mammography guidelines, it will have a high sensitivity and specificity. This test causes very few complications and, in rare cases, seeding or implantation may occur in the needle path $(16,17)$. Pathologists report that the diagnosis of breast cancer using FNA-derived tissue and cells is much easier and more convenient (18). In fact, FNA can make over $30 \%$ of non-definitive diagnoses, $20 \%$ of defective diagnoses, and over $10 \%$ of suspicious diagnoses, but does not diagnose malignancies (19). However, this method has some limitations, including difficulty in making a diagnosis of an in-situ,

(C) 2019 The Author(s); Published by Shahrekord University of Medical Sciences. This is an open-access article distributed under the terms of the Creative Commons Attribution License (http://creativecommons.org/licenses/by/4.0), which permits unrestricted use, distribution, and reproduction in any medium, provided the original work is properly cited. 
invasive cancer. In the case of tiny tumors, it also has low diagnostic accuracy (15).

On the contrary, $\mathrm{CNB}$ has a higher sensitivity than FNA and, if it is image-guided, its sensitivity will increase from $86 \%$ to $98 \%$. Over the past decades, CNB has been used more frequently than FNA for the diagnosis of breast masses (18), and it has been preferred to FNA $(20,21)$; even some researchers have argued that the use of FNA should be abandoned (22). A large body of research on the determination of the diagnostic value of FNA in breast masses have reported its sensitivity and specificity as $90 \%-100 \%$, and its predictive value as $95 \%-100 \%$. In addition, its positive and negative predictive values have been reported to be $95 \%-100 \%$. The false-positive and false-negative rates of the test are also between 1\%-10\% and often $1 \%-5 \%(23-25)$. CNB comparatively causes more complications, mainly including pain and bleeding; particularly, in the women who use anticoagulants such as heparin or warfarin, the risk of bleeding is higher. Moreover, the risk of pneumothorax in CNB is about $1 \%$ (16). CNB is a costly method and has been reported to be an inappropriate strategy due to failure in making an early diagnosis before surgery. It is also argued that the accuracy of this method is influenced by the operator's technical skills as well as the numbers and sizes of the samples taken. Although FNA accuracy is largely influenced by the operator's skill, it is faster, more costeffective, and less invasive, and causes fewer complications $(26,27)$. In the study of Mohajeri et al, FNA was observed to have sensitivity and specificity of $84.8 \%$ and $94.4 \%$, respectively, in comparison with the $\mathrm{CNB}$. The positive predictive value of the FNA test was $95.1 \%$ and its negative predictive value was $82.9 \%$ (28).

Taken together, with regard to the abovementioned material and the results of the previous studies, there is still doubts and controversies about which of the two sampling methods should be considered a diagnostic test for breast cancer $(29,30)$. In addition, various results regarding the sensitivity, specificity, and accuracy of FNA and CNB have been reported from different laboratories with reportedly various causes, including the skill of the aspiration and biopsy performer and the experience of the person who reports the results (31). Therefore, this study aimed to investigate the diagnostic accuracy of FNA compared to $\mathrm{CNB}$ in breast masses.

\section{Materials and Methods}

This study was conducted on the patients with breast masses in Kashani and Hajar hospitals of Shahrekord, Iran, in 2015.

Sample size was determined to be 196 using the following formula, with regard to the similar studies, assuming that the FNA and CNB diagnostic test index was at least $85 \%$, a confidence interval of $95 \%$, and an accuracy of five-fold (32). Finally, 200 patients were enrolled.

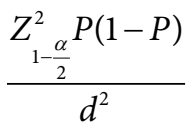

Women with negative (benign) and positive (malignant or suspicious) masses who had unspecified diagnosis were included in the study, while those who had undergone chemotherapy were excluded. Furthermore, lack of knowledge of the final outcome of the masses, lack of continuing the participation, or lack of compatibility of the pathology report with the purpose of the study were other exclusion criteria.

During the study, all the patients initially referred for FNA and CNB completed the informed written consent forms, and then were diagnosed by imaging methods and referred for FNA and CNB.

In general, the FNA is used to make an immediate diagnosis of a lesion, and the CNB is performed to make a definitive diagnosis and to determine prognosis.

In this study, patients referred to the clinic, first received local anesthesia in the area, and then underwent FNA test using $10 \mathrm{cc}$ syringes and 23G needles, and simultaneously $\mathrm{CNB}$ specimens were taken using a special needle for diagnosis. CNB specimens were transferred to the Pathology Department for pathological interpretation.

From the FNA aspirates, 4 slides were prepared and fixed in 96\% ethanol. All the slides were numbered and recorded anonymously. The prepared FNA and CNB slides were transferred to the Pathology Department with a few day interval for cytological interpretation, and interpreted by two pathologists. All the data were recorded in the checklists. Using the data, positive and negative predictive values, sensitivity and specificity, and false-negative and false-positive rates of FNA for breast masses were calculated. The checklist included individual and clinical items (age, type of operation, tumor direction, number of children, oral contraceptive pill taking, lactation, familial history, and first menstrual period), FNA result, CNB result, and pathology report on breast masses.

The data were encoded and entered into the SPSS software version 22.0. Statistical analysis was performed by descriptive statistics (frequency, mean, and standard deviation) and inferential statistics (chi-square) to compare FNA and CNB.

\section{Results}

A total of 200 patients aged 14 to 89 years old (mean age: $40.08 \pm 14.60)$ were studied. Only 1 patient was male. Forty-three of the patients $(21.5 \%)$ had no children and the rest of the patients had at least 1 and at most 11 children (mean: $2.59 \pm 2.10$ ). In 103 cases (51.5\%), the masses were on the right side and in the rest, the masses were on the left side. No binary masses were observed. Out of 200 participants, 50 cases were under modified radical mastectomy and 150 patients underwent mass 
excision. Regarding the use of oral contraceptive pills, 59 patients $(29.5 \%)$ took contraceptive pills for 0.5-14 years (mean: $1.13 \pm 2.27$ ). Considering the family history of cancer, 25 patients $(12.5 \%)$ had such a history. Regarding breastfeeding, most women $(74.5 \%)$ reported having breastfeeding. In our participants, the mean age at first menstruation was $12.21 \pm 1.58$ years (range: $9-18$ )

The FNA results of breast masses were negative for 134 patients (67\%), positive for 38 (19\%), and suspicious for $28(14 \%)$. In addition, the CNB results of breast masses were benign for 138 patients (69\%), consisting of 7 cases of inflammation, 100 cases of fibroadenoma, 2 cases of duct ectasia of the breast, 25 cases of fibrocystic breast disease, and 4 cases of benign lesions; and malignant for $62(31 \%)$ consisting of 60 cases of invasive ductal carcinoma, 1 case of invasive atypical ductal hyperplasia, and 1 case of phyllodes tumor. The frequency distribution of the FNA test results versus the CNB test showed that suspicious FNA results were positive (Table 1, Figure 1). The sensitivity of the FNA test was $83.9 \%$ in comparison with the CNB test for malignant breast masses (Table 1).

In other words, for the 62 patients diagnosed with malignant tumors in the CNB test, the FNA test result was malignant for 52 of them. In addition, this test detected

Table 1. The frequency distribution of the FNA test results versus the CNB test in breast masses

\begin{tabular}{lccc}
\hline \multirow{2}{*}{ FNA } & \multicolumn{3}{c}{ CNB } \\
\cline { 2 - 4 } & Benign & Malignant & Total \\
\hline \multirow{3}{*}{ Benign } & 124 & 10 & 134 \\
& $92.5 \%$ & $7.5 \%$ & $100 \%$ \\
& $89.9 \%$ & $16.1 \%$ & $67 \%$ \\
Malignant & 14 & 52 & 66 \\
& $21.2 \%$ & $78.8 \%$ & $100 \%$ \\
Total (N) & $10.1 \%$ & $83.9 \%$ & $33 \%$ \\
Row percentage & 138 & 62 & 200 \\
Column percentage & $69 \%$ & $31 \%$ & $100 \%$ \\
\hline
\end{tabular}

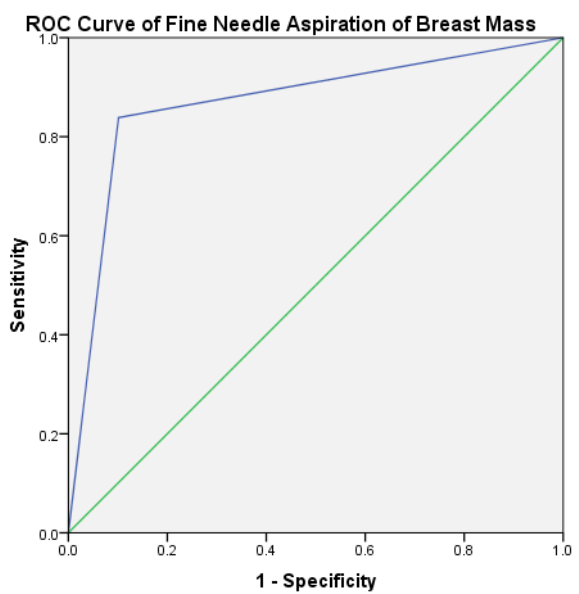

Figure 1. ROC curve analysis in evaluating the diagnostic accuracy of FNA in breast masses.
124 of the 138 benign masses as benign. Therefore, the FNA test had a specificity of $89.9 \%$ in comparison with the $\mathrm{CNB}$ test for benign breast masses. On the other hand, in the FNA test, 10 cases of the malignant masses were detected as benign and 14 cases of benign masses as malignant. Therefore, this test had a false-negative rate of $16.1 \%$ and a false-positive rate of $10.1 \%$.

Based on the results, of 66 patients diagnosed with malignant masses by FNA test, 62 were really malignant, so the positive predictive value of FNA for breast mass was $78.8 \%$. Of the 138 cases diagnosed with benign masses by FNA, 134 cases were benign, so the negative predictive value of FNA for breast mass was $92.5 \%$. The accuracy of FNA test for breast mass in our participants was $0.88 \%$.

\section{Discussion}

Breast cancer is the most common type of cancer in women, so it is obviously logical to consider the need for a simple and inexpensive method that could detect malignant lesions from benign ones. The main purpose of this study was to determine the accuracy of diagnosis made by FNA in comparison with CNB in breast masses. The results of our study showed that the FNA test had a sensitivity of $83.9 \%$ and a specificity of $89.9 \%$ for the detection of breast masses in comparison with the CNB test.

Previous studies have shown that FNA test is more convenient and faster, has less bleeding risk, is more costeffective, causes especially less stress in the patient, and if it has a high diagnostic value, it can be used to diagnose malignancies in breast masses (28). In this study, in the diagnosis of breast masses, false-negative result was $16.1 \%$ and false-positive result was $10.1 \%$, which are within the range of global statistics (3\%-27\%) and acceptable $(5,33)$. In the study of Mohajeri et al, the FNA test, in comparison with $\mathrm{CNB}$, had a sensitivity of $48.8 \%$ and a specificity of $94.4 \%$ for diagnosis of breast tumors; and for breast masses larger than $1 \mathrm{~cm}$, a sensitivity of $76.5 \%$ and a specificity of $100 \%$ was observed. In this study, FNA was $15.2 \%$ false-negative and 5.6\% false-positive (28). In the study of Nakano et al, the false-positive and falsenegative rates of FNA results for small breast lesions were $16.7 \%$ and $3.4 \%$, respectively (34). It is argued that one of the important reasons for false-negative FNA results is taking inadequate specimens. If the FNA is performed by a qualified physician and the cytology is performed by a qualified pathologist using the triple test (mammography, ultrasound, and FNA), it will be definitely more sensitive (35). In our study, the positive predictive value of FNA test for the masses was $78.8 \%$ and the negative predictive value was $92.5 \%$. In the study of Mohajeri et al, the positive and negative predictive values of FNA test were $95.1 \%$ and $82.9 \%$, respectively, while the FNA test accuracy was $89 \%$ (28). In our study, the accuracy of FNA test for breast mass was obtained $0.88 \%$. 
In the study of Moschetta et al, sensitivity, specificity, diagnostic accuracy, and positive and negative predictive values were $97 \%, 94 \%, 95 \%$, and $91 \%$ and $98 \%$ for FNA, and $92 \%, 82 \%, 89 \%$, and $92 \%$ and $82 \%$ for $\mathrm{CNB}$, respectively, compared to the pathology report. The authors concluded that both FNA and CNB had similar diagnostic accuracies in detecting breast lesions (36).

In the study of Nassar, ultrasound-guided FNA was found to be a useful method with high sensitivity and specificity for the diagnosis of breast masses, and therefore could even replace more invasive methods such as CNB (17).

In one study, the accuracy of FNA was investigated in 128 cases of palpable breast masses. The findings showed that FNA had a sensitivity of $91 \%$, a specificity of $97 \%$, a positive predictive value of $97 \%$, and a negative predictive value of $90 \%$ for diagnosis of the masses. It is argued that the technical skill in taking an FNA specimen, as well as coordination between the endocrinologist, surgeon, and pathologist play a major role in the diagnostic value of this method (37). Unlike our findings, in the study of Pagni et al, the CNB test was far superior to the FNA cytology, and it was argued that given that the cytology of FNA is less costly than $\mathrm{CNB}$, its accuracy is lower (78\% versus 93\%) and is less used (32). In another study, the sensitivity and specificity for FNA were $72.5 \%$ and $100 \%$, and the positive and negative predictive values were $81.7 \%$ and $100 \%$, respectively. The study showed that CNB was more sensitive than FNA for the patients with newly diagnosed invasive breast cancer (38).

The predictive value is one of the most important indicators of a diagnostic test. For example, the negative predictive value (indicating the possibility of not being patient when the test result is negative) should be so high that the physician could safely rely on it and be able to surely reject the malignancy in the patient. On the contrary, the positive predictive value (indicating the possibility of not being patient when the test result is positive) also is highly valuable in the malignancies and the doctor can make a diagnosis of malignancy if the result of the test is absolutely strong (28). For patients diagnosed with cancer, appropriate planning leads to an effective treatment, as well as educating the patients about the appropriate therapeutic options (37).

\section{Conclusion}

Considering the high success rate of FNA test in breast masses and few false negative results, it seems that even fewer negative false values could be obtained with more skilled surgeons and pathologists. Therefore, FNA is recommended in breast cancer cases, and given that the test can also be performed on outpatients, it seems that it is more cost-effective than the CNB test. In addition, since it does not require special equipment and can be easily done by different physicians with brief training, it causes minimal complications, and is more tolerable for patients. Further, it can be easily and routinely done and can be used in most cases as an alternative method for CNB for diagnosis of breast masses, if sampling and preparation of the samples and the pathological interpretation are conducted in a sufficiently accurate manner.

Conflict of interests

None.

Ethical considerations

Ethical approval was obtained from the Committee of Ethics, Shahrekord University of Medical Sciences (Code of Ethics: IR.SKUMS.REC.1394.276).

Acknowledgments

Hereby, the financial support of the Research Council of Shahrekord University of Medical Sciences and the cooperation of the professors at this university, as well as all patients are appreciated. This article reported the results of a surgery fellowship thesis (No. 2071) conducted in Shahrekord University of Medical Sciences.

References

1. Ceelen W, Pattyn P, Mareel M. Surgery, wound healing, and metastasis: recent insights and clinical implications. Crit Rev Oncol Hematol. 2014;89(1):16-26. doi: 10.1016/j. critrevonc.2013.07.008.

2. Saika K, Sobue T. Epidemiology of breast cancer in Japan and the US. Japan Med Assoc J. 2009;52(1):39-44.

3. Harirchi I, Karbakhsh M, Kashefi A, Momtahen AJ. Breast cancer in Iran: results of a multi-center study. Asian Pac J Cancer Prev. 2004;5(1):24-7.

4. Moshtagh Eshgh Z, Rahemi Z, Alavi Majd H, Hoviattalab SK, Yaghamaei F. Effects of walking on quality of life of mastectomy patients at selected hospitals of Tehran. Iran J Nurs Midwifery Res. 2011;16(4):299-303.

5. Hunt KK, Newman LA, Copeland EM, Bland KI. The breast. In: Bruncardi FC, Andersen DK, Billiar TR, Dunn DL, Hunter JG, Matthews JB, et al, eds. Schwartz's principles of surgery. 9th ed. NewYork, USA: The McGraw-Hill Companies; 2010:42374.

6. Gunther-Tritsch K, Bojahr B, Ohlinger R. Diagnostic value of palpation and ultrasonography for diagnosing breast cancer recurrence after mastectomy--a comparison. Ultraschall Med. 2009;30(6):577-84. doi: 10.1055/s-0028-1109701.

7. Kim MJ, Kim EK, Kwak JY, Park BW, Kim SI, Sohn J, et al. Sonographic surveillance for the detection of contralateral metachronous breast cancer in an Asian population. AJR Am J Roentgenol. 2009;192(1):221-8. doi: 10.2214/ajr.07.4048.

8. Berg WA, Blume JD, Cormack JB, Mendelson EB, Lehrer D, Bohm-Velez M, et al. Combined screening with ultrasound and mammography vs mammography alone in women at elevated risk of breast cancer. JAMA. 2008;299(18):2151-63. doi: 10.1001/jama.299.18.2151.

9. Wendie A, Dhrur I. Radiologic Techniques and Core Needle Breast Biopsy. In: Silverberg SG, ed. Atlas of breast pathology. Iondon: Philadelphia: WB Saunders; 2002:1-15.

10. Osuch JR, Reeves MJ, Pathak DR, Kinchelow T. BREASTAID: Clinical results from early development of a clinical decision rule for palpable solid breast masses. Ann Surg. 2003;238(5):72837. doi: 10.1097/01.sla.0000094446.78844.ae.

11. Barra Ade A, Gobbi H, Rezende CA, Gouvea AP, de Lucena $\mathrm{CE}$, Reis JH, et al. A comparision of aspiration cytology and core needle biopsy according to tumor size of suspicious breast lesions. Diagn Cytopathol. 2008;36(1):26-31. doi: 10.1002/dc. 20748 .

12. Willems SM, van Deurzen $\mathrm{CH}$, van Diest PJ. Diagnosis of 
breast lesions: fine-needle aspiration cytology or core needle biopsy? A review. J Clin Pathol. 2012;65(4):287-92. doi: 10.1136/jclinpath-2011-200410.

13. Michell MJ. The breast. In: Sutton D, ed. Textbook of radiology and imaging. 7th ed. Edinburgh: Churchill Livingstone; 2003:1451-89.

14. Mendoza P, Lacambra M, Tan PH, Tse GM. Fine needle aspiration cytology of the breast: the nonmalignant categories. Patholog Res Int. 2011;2011:547580. doi: $10.4061 / 2011 / 547580$.

15. Rosa M, Mohammadi A, Masood S. The value of fine needle aspiration biopsy in the diagnosis and prognostic assessment of palpable breast lesions. Diagn Cytopathol. 2012;40(1):2634. doi: $10.1002 / \mathrm{dc} .21497$.

16. Striker TP, Kumar V. Neoplasia. In: Kumar V, Abbas AK, Fausto N, Mitchell RN, eds. Robbins Basic Pathology. 8th ed. Philadelphia: Saunders Elsevier; 2007:173-223.

17. Nassar A. Core needle biopsy versus fine needle aspiration biopsy in breast--a historical perspective and opportunities in the modern era. Diagn Cytopathol. 2011;39(5):380-8. doi: $10.1002 / d c .21433$.

18. Tabbara SO, Frost AR, Stoler MH, Sneige N, Sidawy MK. Changing trends in breast fine-needle aspiration: results of the Papanicolaou Society of Cytopathology Survey. Diagn Cytopathol. 2000;22(2):126-30.

19. Cusick JD, Dotan J, Jaecks RD, Boyle WT Jr. The role of Tru-Cut needle biopsy in the diagnosis of carcinoma of the breast. Surg Gynecol Obstet. 1990;170(5):407-10.

20. Clarke D, Sudhakaran N, Gateley CA. Replace fine needle aspiration cytology with automated core biopsy in the triple assessment of breast cancer. Ann R Coll Surg Engl. 2001;83(2):110-2.

21. Garg S, Mohan H, Bal A, Attri AK, Kochhar S. A comparative analysis of core needle biopsy and fine-needle aspiration cytology in the evaluation of palpable and mammographically detected suspicious breast lesions. Diagn Cytopathol. 2007;35(11):681-9. doi: 10.1002/dc.20721.

22. Litherland JC. Should fine needle aspiration cytology in breast assessment be abandoned? Clin Radiol. 2002;57(2):81-4. doi: 10.1053/crad.2001.0875.

23. Ariga R, Bloom K, Reddy VB, Kluskens L, Francescatti D, Dowlat $K$, et al. Fine-needle aspiration of clinically suspicious palpable breast masses with histopathologic correlation. Am J Surg. 2002;184(5):410-3.

24. Choi HJ, Park IA. Fine needle aspiration cytology of metastatic choriocarcinoma presenting as a breast lump. A case report. Acta Cytol. 2004;48(1):91-4. doi: 10.1159/000326291.

25. Farshid G, Rush G. The use of fine-needle aspiration cytology and core biopsy in the assessment of highly suspicious mammographic microcalcifications: analysis of outcome for 182 lesions detected in the setting of a population-based breast cancer screening program. Cancer. 2003;99(6):357-64. doi: $10.1002 /$ cncr. 11785 .
26. Simsir A, Rapkiewicz A, Cangiarella J. Current utilization of breast FNA in a cytology practice. Diagn Cytopathol. 2009;37(2):140-2. doi: 10.1002/dc.20987.

27. Manfrin E, Mariotto R, Remo A, Reghellin D, Dalfior D, Falsirollo $\mathrm{F}$, et al. Is there still a role for fine-needle aspiration cytology in breast cancer screening? Experience of the Verona Mammographic Breast Cancer Screening Program with realtime integrated radiopathologic activity (1999-2004). Cancer. 2008;114(2):74-82. doi: 10.1002/cncr.23412.

28. Mohajeri GR, Khezreh H, Mehrabi Kushki A, Mohajeri HR, Mohajeri MR, Faghihi M. Evaluation of Fine Needle Aspiration versus Core Needle Biopsy for Breast Cancer Detection. Journal of Isfahan Medical School. 2012;30(175):32-9.

29. Shannon J, Douglas-Jones AG, Dallimore NS. Conversion to core biopsy in preoperative diagnosis of breast lesions: is it justified by results? J Clin Pathol. 2001;54(10):762-5.

30. Cobb CJ, Raza AS. Obituary: "alas poor FNA of breast-we knew thee well!". Diagn Cytopathol. 2005;32(1):1-4. doi: 10.1002/dc.20189.

31. Winer EP, Morrow M, Osborne CK. Malignant tumors of the breast. In: DeVita VT, Hellman S, Rosenberg SA, eds. Cancer: principles and practice of oncology. Philadelphia: Lippincott Williams \& Wilkins; 2001:1651-52.

32. Pagni P, Spunticchia F, Barberi S, Caprio G, Paglicci C. Use of core needle biopsy rather than fine-needle aspiration cytology in the diagnostic approach of breast cancer. Case Rep Oncol. 2014;7(2):452-8. doi: 10.1159/000365141.

33. Bleicher RJ. Management of the palpable breast mass. In: Harris JR, Lippman ME, Morrow M, Kent Osborne C, eds. Diseases of the breast. 4th ed. Philadelphia: Lippincott Williams \& Wilkins; 2010:32-41.

34. Nakano S, Otsuka M, Mibu A, Oinuma T. Significance of fine needle aspiration cytology and vacuum-assisted core needle biopsy for small breast lesions. Clin Breast Cancer. 2015;15(1):e23-6. doi: 10.1016/j.clbc.2014.07.001.

35. Krishnamurthy S, Sneige N, Bedi DG, Edieken BS, Fornage $\mathrm{BD}$, Kuerer HM, et al. Role of ultrasound-guided fine-needle aspiration of indeterminate and suspicious axillary lymph nodes in the initial staging of breast carcinoma. Cancer. 2002;95(5):982-8. doi: 10.1002/cncr.10786.

36. Moschetta M, Telegrafo M, Carluccio DA, Jablonska JP, Rella L, Serio G, et al. Comparison between fine needle aspiration cytology (FNAC) and core needle biopsy (CNB) in the diagnosis of breast lesions. G Chir. 2014;35(7-8):171-6.

37. Motabar AR, Ghoraiian MA. Accuracy of Fine Needle Aspiration in 128 Cases Palpable Breast Masses in Medical Centers of Iran University of Medical Sciences during 20052008. Iran J Surg. 2009;17(1):27-35.

38. Rautiainen $S$, Masarwah A, Sudah M, Sutela A, Pelkonen $\mathrm{O}$, Joukainen $\mathrm{S}$, et al. Axillary lymph node biopsy in newly diagnosed invasive breast cancer: comparative accuracy of fine-needle aspiration biopsy versus core-needle biopsy. Radiology. 2013;269(1):54-60. doi: 10.1148/radiol.13122637. 